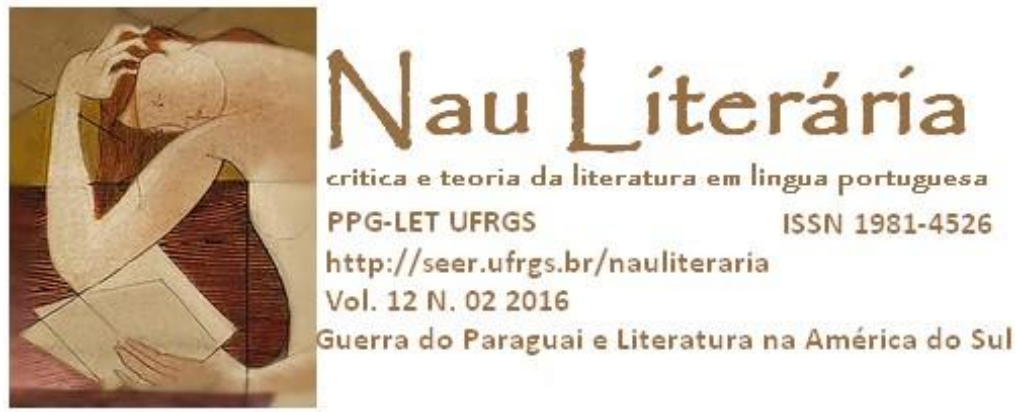

\title{
Roa Bastos, compilador da história paraguaia
}

Karina de Castilhos Lucena

UFRGS

Resumo: Este texto esboça um breve panorama da história paraguaia para expor como Augusto Roa Bastos (Assunção, 1917 - 2005) registrou essa história em sua ficção, em especial nos romances Hijo de hombre (1960) e Yo el Supremo (1974).

Palavras-chave: Augusto Roa Bastos; História do Paraguai; Romance.

Resumen: Este texto plantea un breve panorama de la historia paraguaya para exponer cómo Augusto Roa Bastos (Asunción, 1917 - 2005) registró esta historia en su ficción, especialmente en las novelas Hijo de hombre (1960) y Yo el Supremo (1974).

Palabras clave: Augusto Roa Bastos; Historia de Paraguay; Novela.

Neste 2017 em que se comemora o cinquentenário de Cem anos de solidão (1967) e se lembra que, se estivesse vivo, Gabriel García Márquez (Colômbia, 1927 2014) faria 90 anos; este ano que assistiu à morte de um magnífico escritor, Ricardo Piglia (Argentina, 1941 - 2017); este ano do centenário de outro grande, Juan Rulfo (México, 1917 - 1986); neste 2017 tão difícil em termos políticos, está passando quase despercebida $^{1}$ outra efeméride: o nascimento de Augusto Roa Bastos, ocorrido há exatos 100 anos, em Assunção, Paraguai. Tentamos corrigir essa lacuna com este texto, que tem o objetivo de mostrar como Roa Bastos esteve atento à história paraguaia e

\footnotetext{
${ }^{1}$ Quase despercebida porque a Folha de São Paulo lembrou-se do autor em matéria de 13 de janeiro: <http://sylviacolombo.blogfolha.uol.com.br/2017/01/13/roa-bastos-100-anos-e-uma-necessariahomenagem/>. A Biblioteca Nacional Argentina está exibindo uma mostra sobre o trabalho de Roa Bastos como roteirista de cinema: <https://www.bn.gov.ar/agenda-cultural/augusto-roa-bastos-elsupremo-guionista-1>. No Paraguai, se organizou o "Año del Centenario de Augusto Roa Bastos": <http://www.telam.com.ar/notas/201701/175285-paraguay-homenaje-centenario-nacimiento-augusto-roabastos.html>. De todo modo, se comparado às homenagens rendidas a García Márquez, Piglia e Rulfo, o centenário de Roa Bastos tem recebido menos atenção do jornalismo e da crítica literária.
} 
como esta se materializa em sua ficção, em especial nos romances Hijo de hombre (1960) e Yo el Supremo (1974).

Embora tivesse nascido na capital paraguaia, Roa Bastos passou a infância em Iturbe, nas selvas do Alto Paraná, sul do país, para onde a família se transferiu porque o pai assumiu a administração de um engenho de açúcar ${ }^{2}$. Essa mudança para o interior põe Roa Bastos diante de um aspecto tipicamente paraguaio: a convivência entre a língua espanhola e o guarani, convivência esta que, com o tempo, será marca de toda a nação. É importante destacar essa especificidade paraguaia. Um país constitucionalmente bilíngue, onde a língua indígena também tem status de idioma oficial, dá mostras de uma conexão entre o estrangeiro e o local, a cidade e o campo que, se não é harmônica, pelo menos discrepa da antítese que define os grandes países latino-americanos (Argentina, Brasil e México, por exemplo) em que capital e interior andam em ritmos quase opostos. Roa Bastos atentou para a dinâmica bicultural paraguaia e nos seus textos está presente esse registro.

Mas como contatos culturais estão sempre marcados por tensões, a imersão do jovem Roa Bastos na cultura indígena é freada pela distinção de classe. Embora sua família não fosse exatamente de posses, na mentalidade de Lucio Roa, pai do escritor, estava a posição superior da língua espanhola. Segundo Sergio Ramírez:

[...] lejos de dirigir el ingenio, el padre llegó como un simple peón que seguía en su labor de talar árboles con el hacha, ya que el ingenio estaba en construcción y los campos para sembrar la caña de azúcar en proceso de ser desbrozados. Con sus manos construyó los pupitres donde Augusto y su hermana Rosa, la mayor de los dos, se sentaban a recibir las lecciones que él mismo les impartía, una hora diaria después de la siesta de la tarde, porque nunca asistieron a la escuela pública. Lucio no quería que los niños se contaminaran de la lengua guaraní, que veía como una degradación, y luego les daría a leer a Quevedo, a Cervantes, y a San Agustín. En el patio se izaba a diario la bandera nacional, y había una campana que sonaba llamando al inicio de las clases (2011, p. 8).

Ainda que a história pareça adotar um tom mais de ficção do que de documento - Sergio Ramírez, escritor, diz que a ouviu de Tomás Eloy Martínez, outro escritor melhor não duvidar da vontade de distinguir-se socialmente, em qualquer tempo, mas em especial nas nacionalistas primeiras décadas do século XX.

No mesmo texto (2011, p. 9), Ramírez afirma que em 1930, aos treze anos de idade, Roa Bastos compôs a peça La carcajada, que pode ser lida como uma referência à organização militar que derivaria na Guerra do Chaco, conflito armado entre Paraguai

\footnotetext{
${ }^{2}$ As informações biográficas sobre Roa Bastos foram retiradas do prólogo à edição de Hijo de hombre da Eterna Cadencia (Buenos Aires, 2011), assinado pelo escritor nicaraguense Sergio Ramírez.
} 
e Bolívia, de 1932 a 1935. Esse primeiro impulso de anotar na ficção a história de seu país vai ser uma das marcas da narrativa de Roa Bastos. Antes de comentar essa narrativa, vale destacar alguns episódios-chave da história paraguaia, para entendermos a singularidade dessa formação histórica.

Durante a colônia, se a presença da Companhia de Jesus e o estabelecimento das missões jesuíticas guaranis (1607 - 1768) deixaram no território, por um lado, as marcas da imposição de religião, costumes, sistemas culturais e, por outro, os rastros da rebelião indígena, é preciso reconhecer que dessa tensão surgiu uma sofisticada organização social e econômica que despertou o interesse das autoridades espanholas e as fez arruinarem essas fundações quando da negativa de suas exigências. A missão jesuítica, essa complexa sociedade, que por ser complexa não é menos violenta, assinala na história paraguaia essa dialética entre desenvolvimento e autoritarismo que vai definir também períodos subsequentes.

Com a independência da Espanha, em 1811, o Paraguai segue um destino em parte compartilhado com outros países latino-americanos: surge uma figura dominante que toma para si a tarefa de estruturar a recém-criada nação. No caso paraguaio, essa figura é José Gaspar Rodríguez de Francia y Velasco, o famoso doutor Francia, Supremo Ditador Perpétuo da República do Paraguai, que Roa Bastos transformará no personagem central de Yo el Supremo, e que já aparece em Hijo de hombre como uma grande sombra patriarcal (RAMÍREZ, 2011, p. 12). Carlos Fuentes, no texto Augusto Roa Bastos: el poder de la imaginación ${ }^{3}$, comenta a atuação de Francia e localiza essa personalidade no conjunto das tantas que surgiram na América pós-independências:

En Paraguay, Francia decidió convertir la necesidad en virtud, transformando su poder parroquial en poder nacional. Convirtió el hecho del aislamiento paraguayo en pretexto para salvar a su país de la absorción por Argentina o Brasil. Nombrado por sí mismo "El Supremo", Francia prohibió el comercio, los viajes e incluso el servicio postal entre Paraguay y el mundo exterior. [...] El Supremo colocó un enorme aviso de NO HAY SALIDA a las puertas de su feudo. También arropó su chovinismo de fierro con una capa populista. Por necesidad, su república introvertida había de ser autárquica. Francia creó una economía de subsistencia, favoreció da política de la chusma, atacó y debilitó a la Iglesia, pero, al cabo, protegió y fortaleció a los intereses oligárquicos tradicionales. $\mathrm{Su}$ prolongado reino demuestra un hecho generalmente ignorado de nuestra historia: el nacionalismo latinoamericano tiene sus orígenes en la derecha, más que en la izquierda intelectualmente orientada hacia el internacionalismo. También ilumina un hecho bastante conocido: el populismo despótico disfraza la parálisis impuesta por el tirano a la sociedad. Hay la impresión del movimento. Pero nada cambia (2011, p. 12-13).

\footnotetext{
${ }^{3}$ O texto é de 1993 e integra o livro Geografía de la novela (Alfaguara), de Fuentes. Utilizamos aqui a versão que serve de prólogo para a edição de Yo el Supremo da editora Random House Mondadori, 2011.
} 
Fuentes fala de Francia, mas poderia estar falando de Juan Manuel de Rosas, por exemplo, o ditador argentino de atuação semelhante na primeira metade do século XIX. A comparação nos ajuda a modular o ponto de vista de Fuentes, ou pelo menos a sinalizar que palavras como populismo são traiçoeiras ${ }^{4}$. A historiografia argentina tem revisado o discurso sobre Rosas, em geral, escrito por seus adversários ideológicos - os unitários, de orientação liberal e visão de mundo cosmopolita, em oposição ao federalismo de Rosas, de viés militar e interessado no dado local. Embora essa revisão historiográfica não exima Rosas (nem Francia, nem qualquer ditador) das atrocidades cometidas, serve para mostrar o quanto governos que de alguma forma se interessaram pelas classes populares, logo receberam a etiqueta rebaixada de populistas.

Assim como parte importante da ficção argentina no século XIX reagiu à imagem de Rosas, Francia vai estender sua sombra à literatura paraguaia, dentro da qual Roa Bastos ocupa papel destacado. Como já dissemos, o principal romance do escritor, Yo el Supremo, narra, a partir da perspectiva de Francia, os bastidores do poder. Voltaremos a esse livro em seguida.

Francia governou o Paraguai até 1840, ano de sua morte. Foi sucedido por Carlos Antonio López, sobrinho de Francia, que nos vinte anos em que esteve no poder (morreu em 1862) tratou de reverter a política de isolamento de seu antecessor. Nesse período, o Paraguai acompanha a direção modernizadora que define a maioria dos países latino-americanos na segunda metade do século XIX, a chegada das linhas férreas, das primeiras fundições, dos imigrantes. Na América hispânica ${ }^{5}$, a educação pública, gratuita e obrigatória começa a ser uma realidade.

Em 1865, a aparente prosperidade paraguaia vem abaixo. A Guerra da Tríplice Aliança, Grande Guerra ou Guerra do Paraguai vai estender-se até 1870 e entrará para a história como o conflito mais sangrento da América do Sul, praticamente dizimando a população do país. Ainda Ramírez:

[...] murió un millón de los habitantes del país, entre ellos el propio mariscal presidente, crucificado por las tropas brasileñas en el cerro Corá, y sobrevivieron apenas doscientos mil, más que nada niños, mujeres y ancianos, y un puñado de hombres. Encima de eso, a consecuencia de la derrota, el Paraguay debió sufrir por varios años la ocupación de

\footnotetext{
${ }^{4}$ Para um debate aprofundado sobre o populismo na América Latina e as distorções impostas ao conceito ao longo do tempo, ver Ernesto Laclau, La razón populista. No Brasil, a editora paulista Três Estrelas publicou a tradução, a cargo de Carlos Eugênio Marcondes de Moura, em 2013, com o título A razão populista.

${ }^{5}$ É importante essa distinção. Enquanto alguns países hispânicos começam a propor educação pública a todos os cidadãos a partir dos anos 1850, o Brasil amargaria ainda quase quarenta anos de escravidão.
} 
Brasil, bajo una especie de virreinato, además de la desmembración de su territorio (2011, p. 13-14).

O marechal presidente era o célebre Francisco Solano López, filho de Carlos Antonio López, que havia sucedido o pai depois de sua morte, em 1862. Com o fim da Guerra, como não poderia ser diferente, o Paraguai vai minguar por longos anos. Concentração de terra, conflitos agrários, miséria, analfabetismo vão definir a sociedade paraguaia do final do século XIX e início do XX. Como já dissemos, em 1932, nova guerra, a do Chaco, contra a Bolívia. Em 1935, assinado o tratado de paz, o Paraguai é um país devastado. É nesse país que vai transcorrer a infância e a juventude de Roa Bastos (nascido em 1917, vale lembrar). É nesse país que Roa Bastos vai viver até 1947, quando se vê obrigado a exilar-se em Buenos Aires depois de ser taxado de conspirador comunista pelo governo do general Higinio Morínigo. Roa Bastos trabalhava então na redação do jornal El País e seus textos começavam a incomodar.

Em Buenos Aires, publica seu primeiro livro de contos, El trueno entre las hojas, em 1953, pela Editorial Losada. A literatura, no entanto, não lhe garante a subsistência, e Roa Bastos concilia atividades das mais diversas: de professor, redator, roteirista de cinema a vendedor de seguros e funcionário de hotel. Seu exílio iria durar muitos anos mais porque agora o Paraguai seguia a regra de tantos outros países latinoamericanos que penaram sob as ditaduras civil-militares da segunda metade do século XX. O general Alfredo Stroessner governaria o Paraguai de 1954 a 1989. Segundo Ramírez, "derrocado por fin en 1989 por un golpe de estado que le dio su consuegro, el general Andrés Rodríguez. La historia del Paraguay seguía siendo una historia familiar" (2011, p. 21). Com a queda de Stroessner, Roa Bastos volta ao Paraguai, embora a fama internacional (recebeu o Prêmio Cervantes em 1989) o envolva em viagens constantes. Em seus últimos anos, fixa residência em seu país natal. Morre em Assunção em 2005.

Testemunha de uma história aterradora, Roa Bastos se dedicaria ao apuro técnico para transportá-la à ficção. Tanto Hijo de hombre quanto Yo el Supremo (escritas no exílio parte portenho, parte parisiense) são romances de grande sofisticação narrativa. Hijo de hombre, publicada originalmente em 1960, e revisada pelo autor ao longo da vida, a ponto de um novo capítulo ser incluído em 1983, inicia aquilo que Roa Bastos chamou de trilogia paraguaia, que se completaria com Yo el Supremo (1974) e El fiscal (1993). No primeiro romance, a narrativa registra as duas cosmovisões que formam o Paraguai: a indígena e a espanhola. Nas palavras de Roa Bastos: 
En la literatura de este país, las particularidades de su cultura bilingüe, única en su especie en América Latina, constriñe a los escritores paraguayos, en el momento de escribir en castellano, a oír los sonidos de un discurso oral informulado aún, pero presente ya en la vertiente emocional y mítica del guaraní. Este discurso, este texto no escrito, subyace en el universo lingüístico bivalente hispano-guaraní, escindiendo entre la escritura y la oralidad. Es un texto en que el escritor no piensa, pero que lo piensa a él. Así, esta presencia lingüística del guaraní se impone desde la interioridad misma del mundo afectivo de los paraguayos. Plasma su expresión coloquial cotidiana, así como la expresión simbólica de su noción del mundo, de sus mitos sociales, de sus experiencias de vida individuales y colectivas (2011a, p. 29-30).

No texto de Hijo de hombre está presente essa busca pelo ritmo da oralidade derivado da presença da língua indígena no espanhol paraguaio. Talvez o centro do relato seja o velho Macario, típico representante da sabedoria popular, a figura quase mítica que concentra a memória coletiva. Já nas primeiras páginas do romance, ele é descrito assim:

El que mejor conocía la historia era el viejo Macario. Esa y muchas otras. [...] Era un maravilloso contador de cuentos. Sobre todo, un poco antes de que se pusiera tan chocho para morir. Era la memoria viviente del pueblo. Ya sabía cosas de más allá de sus linderos. Él mismo no había nacido allí. Se murmuraba que era un hijo mostrenco de Francia. En el libro de Crismas estaba registrado con ese apellido. Macario habría nacido algunos años después de haberse establecido la Dictadura Perpetua. [...] Lo escuchábamos con escalofríos. Y aquella época inescrutable nos sapecaba la cara a través de la boca del anciano. Siempre hablaba en guaraní. El dejo suave de la lengua india tornaba apacible el horror, lo metía en la sangre. Ecos de otros ecos. Sombras de sombras. Reflejos de reflejos. No la verdad tal vez de los hechos, pero sí su encantamiento (2011a, p. 39-40, sublinhados meus).

Nesse pequeno fragmento está o projeto literário que Roa Bastos desenhou para seu primeiro romance. Narrar a história paraguaia (Francia, a Ditadura Perpétua) pelo viés da cultura popular (os contos de Macario em guarani), deixando evidente o efeito nefasto que essa história de arbitrariedades teve precisamente nessa representação popular, já que esse Macario que enuncia a voz do povo é um mendigo à beira da morte.

O projeto literário de Yo el Supremo, por sua vez, é um tanto mais ousado: ingressar na consciência do ditador e deixá-lo narrar, em primeira pessoa, seu plano de poder. O livro que lemos é um emaranhado de documentos, bem ao estilo narrativo das principais obras do chamado boom (Rayuela, de Cortázar, por exemplo): o diálogo - na verdade as ordens - do Supremo com seu secretário, folhetos, cartas, o caderno privado do ditador, tudo isso ordenado por um compilador que, ao final do livro, redige uma nota apresentando-se como simples copista, como alguém que testemunhou a história e se incumbiu da tarefa de registrá-la:

Esta compilación ha sido entresacada - más honrado sería decir sonsacada - de unos veinte mil legajos, éditos e inéditos; de otros tantos volúmenes, folletos, periódicos, 
correspondencias y toda suerte de testimonios ocultados, consultados, espigados, espiados, en bibliotecas y archivos privados y oficiales. Hay que agregar a esto las versiones recogidas en las fuentes de la tradición oral, y unas quince mil horas de entrevistas grabadas en magnetófono, agravadas de imprecisiones y confusiones, a supuestos parientes y contraparientes de El Supremo, que se jactó siempre de no tener ninguno; a epígonos, panegiristas y detractores no menos supuestos y nebulosos. Ya habrá advertido el lector que, al revés de los textos usuales, éste ha sido leído primero y escrito después. En lugar de decir y escribir cosa nueva, no ha hecho más que copiar fielmente lo ya dicho y compuesto por otros. No hay pues en la compilación una sola página, una sola frase, una sola palabra, desde el título hasta esta nota final, que no haya sido escrita de esa manera (2011b, p. 585).

No desfecho do livro, Roa Bastos se mistura ao compilador que inventou. Esse personagem que se revela como organizador no texto que acabamos de ler executa o projeto literário que Roa Bastos traçou para si: compilar a história paraguaia manifesta nas mais diferentes fontes da tradição letrada e da cultura popular. Não exageramos ao dizer que Roa Bastos foi o principal compilador da história paraguaia, ao menos no plano literário.

Ainda sobre Yo el Supremo, um comentário de Carlos Fuentes potencializa a leitura de Roa Bastos como um escritor interessado no apontamento da história. Segundo o escritor mexicano (2011, p. 10), no final dos anos 1960, em pleno boom da literatura latino-americana, ele e Vargas Llosa se encontraram em Londres e arquitetaram um projeto: um volume coletivo de narrativas curtas, cada uma delas dedicada a um tirano latino-americano. Participariam da empreitada, além dos dois idealizadores, Roa Bastos, Cortázar, Miguel Otero Silva, Juan Bosch, García Márquez, Alejo Carpentier, José Donoso e Jorge Edwards. A proposta fracassou, mas três dos convidados levaram adiante a ideia e publicaram, quase simultaneamente, romances em primeira pessoa cujo narrador é um ditador. Além de Yo el Supremo, saíram, em 1974, El recurso del método, de Alejo Carpentier, e em 1975, El otoño del patriarca, de Gabriel García Márquez. Esses três romances inauguram uma tradição literária latinoamericana chamada romance de ditador, ainda vigente com La fiesta del chivo (2000), de Mario Vargas Llosa, para ficar com um exemplo excelente.

$\mathrm{O}$ romance de ditador se tornou uma estética tão contundente que o crítico italiano Franco Moretti a utiliza para explicar sua teoria sobre o estilo indireto livre. No livro A literatura vista de longe (2005, tradução brasileira de 2008), ele analisa o discurso dos narradores-ditadores dos romances latino-americanos:

No romance de Roa Bastos - assim como em $O$ recurso do método, de Carpentier, e em $O$ general em seu labirinto [sic], de García Márquez, os outros dois romances de ditador saídos em 1974, o ano sucessivo ao putsch militar contra Allende - o "Eu" de El Supremo é muito superior, e o indireto 
livre permanece inevitavelmente circunscrito a um papel periférico. Com Mario Vargas Llosa, porém, a técnica desloca-se para o centro do quadro e libera todo o seu potencial polêmico (2008, p. 149).

Seja pela anotação cuidadosa da história paraguaia, que compreendeu em sua complexa dinâmica bicultural, seja pelo aporte técnico à forma de narrar, Augusto Roa Bastos inscreveu seu nome entre os grandes escritores latino-americanos do século XX. Neste 2017 em que faria cem anos, há muitas razões para celebrá-lo.

\section{Referências}

FUENTES, Carlos. Augusto Roa Bastos: El poder de la imaginación [Prólogo]. In: ROA BASTOS, Augusto. Yo el Supremo. Buenos Aires: Randon House Mondadori, 2011.

LACLAU, Ernesto. A razão populista. Tradução de Carlos Eugênio Marcondes de Moura. São Paulo: Três Letras, 2013.

MORETTI, Franco. A literatura vista de longe. Tradução de Anselmo Pessoa Neto. Porto Alegre: Arquipélago, 2008.

RAMÍREZ, Sergio. Un friso oscuro y esplendoroso [Prólogo]. In: ROA BASTOS, Augusto. Hijo de hombre. Buenos Aires: Eterna Cadencia, 2011.

ROA BASTOS, Augusto. Hijo de hombre. Buenos Aires: Eterna Cadencia, 2011a. Yo el Supremo. Buenos Aires: Randon House Mondadori, 2011 b. 